\title{
The Influence of Mineral Salt Interface Modifier to Pavement Rubber Concrete Strength
}

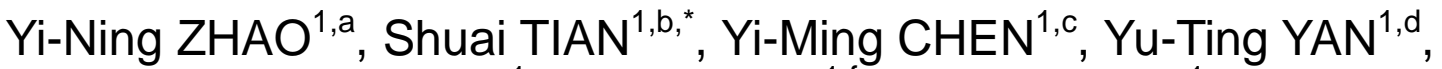 \\ Shao-Yue JIN ${ }^{1, e}$, Xu ZHANG ${ }^{1, f}$, Guang-Bao LI ${ }^{1, g}$
}

${ }^{1}$ School of Civil Engineering. University of Science and Technology Liaoning AnShan, 114051

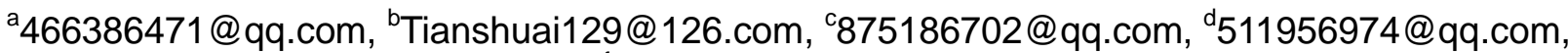

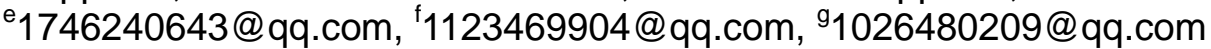

*Corresponding author

Keywords: Mineral Salt, Rubber Concrete, Interface Modifier, The Encapsulating Aggregate Method.

\begin{abstract}
The experiment researched the influence of mineral salt to pavement rubber aggregate and the interface shear strength of cement matrix, which also discussed the mechanism of action about mineral salt interface modifier .Research showed: mineral salt has a big effect on the compressive strength of rubber concrete but nothing to splitting strength. The longer time of rubber aggregate was soaked by mineral salt, the more apparent of modification effect. As modifier, the optimal usage of $\mathrm{C}_{\mathrm{a}} \mathrm{Cl}_{2}$ is $10 \%$ of rubber powder's weight. Rubber powder after treatment fits the mixing process of cement paste encapsulating aggregate method. Organic salt isn't much suitable for being modifier.
\end{abstract}

\section{Introduction}

Mixing rubber powder what made by waste tire into the Road-Engineering, which not only benefit eliminate "Black Pollution", but also has positive meaning to the fragility, shock resistance, crack resistance, insulation and sound absorption of cement concrete. However, there are some shortcomings. Rubber powder is an organic material, which mainly made up by ionic compound so that its surface has intense hygroscopy caused surface properties between two material is entirely different resulting their surface was hard to combine. And reducing the strength, workability of concrete. After the treatment of rubber powder, the interfacial bond between rubber and matrix will improve and strengthen. Writer through experiment and research found that pretreated mineral salt has most outstanding modification effect on improving the bond strength between cement matrix and pavement rubber powder. This paper from mineral salt to research that the influence of mineral salt to interface bond strength between pavement rubber aggregate and concrete matrix. Finally getting the adequate intake and best construction technology of mineral salt modifier.

\section{Experiment}

\section{Material}

Cement: level P042.5 ordinary Portland cement produced by Anshan cement plant, which measured $28 \mathrm{~d}$ compressive strength is $48.4 \mathrm{Mpa}$ and thickness is $3100 \mathrm{Kg} / \mathrm{m}^{3}$. Sand: natural sands, max grain size is $5 \mathrm{~mm}$, continuous grading, fineness modulus is 2.78 , medium sand, apparent density is $2630 \mathrm{Kg} / \mathrm{m}^{3}$. Macadam:limestone, $5 \sim 31.5 \mathrm{~mm}$,continuous grain size, fresh calcarea, apparent density is $2670 \mathrm{Kg} / \mathrm{m}^{3}$. Rubber powder: Produced by Tianjing rubber powder factory, mix $8,15,20,40,60 \mathrm{mesh}$ with average density is $1050 \mathrm{Kg} / \mathrm{m}^{3}$. Water: Ordinary tap water.

\section{Method}

The experiment choose $\mathrm{C}_{\mathrm{a}} \mathrm{Cl}_{2}, \mathrm{Al}_{2}(\mathrm{SO} 4)_{3}$, sodium acetate and ammonium acetate as rubber powder modifier. The modification process is as following: Firstly, according certain percentage of rubber powder's weight to get modifier and confected it into salt solution of certain concentration. 
Secondly, soaked the rubber powder on the salt solution for $30 \mathrm{~min}$ or $24 \mathrm{~h}$ and other length of time. Finally, drying it and packaging for next step. In order to let salt material fully immersed in rubber powder surface with certain depth, soaking sticking to dry rubber powder surface by crystal morphology. Those measure makes modifier improving the shear strength between rubber powder and cement paste during the production.

\section{Mix Design}

<specification for Highway cement concrete pavement Design>said that if high-type highway require anti-freeze, there are some limited as follow: Max water-cement is 0.42 ; min unit cement dosage is $320 \mathrm{Kg} / \mathrm{m}^{3}$; Max unit water dosage is $160 \mathrm{Kg} / \mathrm{m}^{3}$, sand fineness modulus is between 2.5 and 2.8.Sand ratio is between $32 \%$ and $36 \%$.Combine with the design, proportioning design can estimated.

Proportioning design of common concrete: $m_{c o}: m_{w o}: m_{s o}: m_{g o}=372: 160: 679: 1206$

Proportioning design of rubber concrete: $m_{c o}: m_{w o}: m_{s o}: m_{g o}: m_{\text {rubberpowdr }}=372: 160: 574: 1207: 42$

In two proportioning design, sand ratio is $35 \%$ in same and rubber powder mixed low dosage of $4 \%[1]$ into concrete while sand ratio should consider the effect of rubber powder.

\section{Mixing process}

Firstly, mixing rubber powder into cement and stir evenly. Secondly, Mixing up coarse aggregate and fine aggregate. Finally, adding water. The purpose of those step is that remain modifier on rubber powder's surface to improve interfacial bond between rubber powder and cement concrete.

\section{Result and Analysis}

\section{The Influence of the Time Length of Mineral Soaked by Mineral Salt Solution to the Strength}

According to $5 \%$ weight of rubber powder got $\mathrm{Al}_{2}(\mathrm{SO} 4)_{3}$ and $\mathrm{CaCl}_{2}$, then confected them into solution of those salt solution by different time. Using the treatment rubber powder product rubber concrete specimens and comparing with ordinary concrete and no-treatment rubber concrete specimens. The test results of concrete's $28 \mathrm{~d}$ compressive strength are as chart 1 :

Tab.1 The concrete's $28 \mathrm{~d}$ compressive strength with different length of soaking time(MPa)

\begin{tabular}{c|c|c|c|c}
\hline modifier & \multicolumn{2}{|c|}{$\mathrm{CaCl}_{2}$} & \multicolumn{2}{c}{$\mathrm{Al}_{2}\left(\mathrm{SO}_{3}\right)_{3}$} \\
\hline Soaking time & $30 \mathrm{~min}$ & $24 \mathrm{~h}$ & $30 \mathrm{~min}$ & $24 \mathrm{~h}$ \\
\hline Compressive strength & 39.3 & 41.1 & 36.6 & 40.1 \\
\hline
\end{tabular}

Under the same condition, ordinary concrete's $28 \mathrm{~d}$ compressive strength is $45.2 \mathrm{Mpa}$ while no-treatment rubber concrete is $36.3 \mathrm{Mpa}$. The data of chart 1 showed that the longer time of rubber powder was soaked by mineral salt solution, the more improvement the compressive strength, the higher the compressive strength, the more close to the strength requirement of concrete pavement.

\section{The Influence of Mineral Salt to Compressive Strength}

According to $1 \%, 3 \%, 5 \%$ and $7 \%$ weight of rubber powder got $\mathrm{C}_{\mathrm{a}} \mathrm{Cl}_{2}$, the confected them into the solution with same volume but different concentration. Soaked the rubber powder respectively for 24h.Using the pretreatment rubber powder produced concrete specimens and comparing with ordinary concrete specimens and no-treatment rubber concrete. The result is as chart 2:

Tab.2 The concrete's $28 \mathrm{~d}$ compressive strength with different concentration of $\mathrm{Cacl}_{2}(\mathrm{MPa})$

\begin{tabular}{c|c|c|c|c}
\hline Mineral salt dosage & $1 \%$ & $3 \%$ & $5 \%$ & $7 \%$ \\
\hline Compressive strength & 40.5 & 41.2 & 41.1 & 34.5 \\
\hline
\end{tabular}

The data of chart 2 shows: The treatment rubber concrete has higher strength when the dosage of $\mathrm{C}_{\mathrm{a}} \mathrm{Cl}_{2}$ is between $1 \%$ and $5 \%$, which indicated the lower dosage of $\mathrm{C}_{\mathrm{a}} \mathrm{Cl}_{2}$ is benefit to the strength of 
rubber concrete. On the other side, strength of concrete sharply decreased when the dosage of $\mathrm{C}_{\mathrm{a}} \mathrm{Cl}_{2}$ is $7 \%$, which showed too much dosage of $\mathrm{C}_{\mathrm{a}} \mathrm{Cl}_{2}$ was harmful to concrete's strength.

Analysis with experience including that when dosage of $\mathrm{C}_{\mathrm{a}} \mathrm{Cl}_{2}$ is $5 \%$, the proportion of $\mathrm{Cacl}_{2}$ adhere to the rubber powder is $84.4 \%$. And when the dosage of $\mathrm{Cacl}_{2}$ is $1 \%$, the proportion is almost $100 \%$.This phenomenon shows that the less mineral salt used, the proportion of stick is higher. So there are more benefit from the point of compressive strength, the proportion of stick and economy when the dosage of mineral salt is $1 \%$.

\section{The Influence of Mineral Salt to Splitting Strength}

According to $5 \%$ weight of rubber powder got $\mathrm{C}_{\mathrm{a}} \mathrm{Cl}_{2}$ and $\mathrm{Al}_{2}(\mathrm{SO} 4)_{3}$, then confected them into solution of mixture concentration was $10 \%$.Soaked the rubber powder respectively for $24 \mathrm{~h}$.Using the treatment rubber powder product concrete specimens and comparing with ordinary and no-treatment rubber concrete. The result about $28 \mathrm{~d}$ splitting strength of concrete was as chart 3 :

Tab.3 The 28d splitting strength of treatment rubber concrete(MPa)

\begin{tabular}{c|c|c}
\hline modifier & $\mathrm{C}_{\mathrm{a}} \mathrm{Cl}_{2}$ & $\mathrm{Al}_{2}(\mathrm{SO} 4)_{3}$ \\
\hline Splitting strength & 3.42 & 3.56 \\
\hline
\end{tabular}

Under the same condition, the $28 \mathrm{~d}$ splitting strength of ordinary concrete is $4.75 \mathrm{Mpa}$, while no-treatment concrete is $3.55 \mathrm{Mpa}$. The data of chart 3 indicated that mineral salt modifier is almost no effect on the splitting strength of rubber concrete and there are no improvement on strength.

\section{The Strength Influence Comparing between Mineral Salt and Organic Salt}

According to $5 \%$ weight of rubber powder got sodium acetate and ammonium acetate ,then confected them into solution of mixture concentration was $10 \%$.soaked the rubber poeder respectively for $24 \mathrm{~h} .$. Using the treatment rubber powder product concrete specimens and comparing with ordinary concrete and no-treatment rubber concrete. The test result about $28 \mathrm{~d}$ splitting strength and compressive strength of concrete is as chart 4 :

Tab.4 The splitting strength and compressive strength of rubber concrete with treatment of mineral salt(MPa)

\begin{tabular}{c|c|c}
\hline modifier & sodium acetate & ammonium acetate \\
\hline Compressive strength & 35.8 & 30.4 \\
\hline Splitting strength & 3.1 & 3.0 \\
\hline
\end{tabular}

The data chart 4 showed that: organic salt almost has no effect on the splitting and compressive strength of rubber concrete but there is a decrease tendency. In a word, organic salt is not fit to be modifier but mineral salt is

\section{The Discussion about the Mechanism of Action of the Mineral Salt Modifier to the Interface Interfacial Transition Zone}

Inerrfacial transition zone is a weak part of concrete. This part gathered acicular crystal and threadiness crystal and most of them is a kind of layer structure along the axial. The zone has lots of honeycomb and it was loose structure. The mechanical property about spread and impervious of it was weak than cement matrix. This phenomenon has effect on the strength, elasticity modulus, skrinkage and transmission of concrete. Literature shows that the zone of cobblestone-cement matrix is about $85 \mu \mathrm{m}$. While the lager range of the zone, the weaker of interface bond. So it takes negative to concrete strength. Organic modifier or alkaline-acid class only could take care of the surface of rubber particle, which cannot changing the zone's property of cement matrix nicely. On the contrary, mineral salt could improve hardness of the zone and changing the form of crystal. The phenomenon above-mentioned explained that mineral modifier is better than other modifier. 
Why interfacial transition zone was weak for its forming process. Firstly, in the new tamping concrete along aggregate around, there was a water film. The film not only result in the water cement ratio of aggregate's surface was lager than cement itself and the concentration of cement particle around the surface of rubber powder particle was close to 0,but also making the bond between cement and rubber decreased. Then, cement paste react in the zone, which product the etteringite and calcium hydroxide. And two product of it is layer structure along the axial, which has tiny crystal bond force and VDW. For the weak of the zone, it cannot translate stress nicely. The result of it is that concrete's rigidity is tiny. Experiment telling why mineral salt modifier do little to the splitting strength mainly due to the mineral salt doesn't totally changing the layer structure of the zone. The zone was still easy to snap, which is shortcoming of mineral salt modifier.

The reason why the dosage of mineral salt was not suitable for too much is also can explained by interfacial transition zone. $\mathrm{Al}_{2}(\mathrm{SO} 4)_{3}$ and $\mathrm{C}_{\mathrm{a}} \mathrm{Cl}_{2}$ are the early strength agent. $\mathrm{By}$ the mixing process of cement paste encapsulating aggregate method. The exist of mineral salt made the interfaical transition zone had fast reaction but the reaction of cement matrix is slower. Because of the late reaction of cement matrix, which caused to the lost of early period's strength in the zone. Moreover, the zone will appear gap and small opening. The faster early strength increasing, the more harmful effect of the late period's strength. Only when the dosage of mineral salt is not too much, which could sure for the strength of the zone and no strength lost.

\section{The Hydration Reaction of Mineral Salt}

Mineral salt mainly including chloride, sulfate, nitrate, nitrite, carbonate and so on. Mineral salt accelerated the early hydration of cement so that the concrete has certainly viscosity and strength in the early period. For example, $\mathrm{C}_{\mathrm{a}} \mathrm{Cl}_{2}$ reacted with $\mathrm{C}_{3} \mathrm{~S}$ created hydrated calcium aluminate what almost insoluble in water and $\mathrm{C}_{\mathrm{a}} \mathrm{Cl}_{2}$ reacted with $\mathrm{Ca}(\mathrm{OH})_{2}$ created calcium oxychloride what has tiny solubility. Then, decreasing the concentration of $\mathrm{Ca}_{(\mathrm{OH})_{2}}$ in cement paste, which accelerated the form of the structure of the cement paste and it was benefit to the early strength. Taking aluminum sulfate as an example, mixing it into concrete could happen the following reaction: $\mathrm{Al}_{2}\left(\mathrm{SO}_{4}\right)_{3}+3 \mathrm{C}_{\mathrm{a}}(\mathrm{OH})_{2} \rightarrow 3 \mathrm{C}_{\mathrm{a}} \mathrm{SO}{ }_{4}+2 \mathrm{Al}(\mathrm{OH})_{3}$. Calcium sulfate product in the reaction dispensed homogeneously. The product could react with $\mathrm{C}_{3} \mathrm{~A}$ easily and forming hydrated calcium acuminate quickly. And the reaction as above-mentioned can also accelerated the hydration of $\mathrm{C} 3 \mathrm{~S}$, which improve the rate of hardening of concrete for a lot and its helpful to the form of the early strength.

If mineral salt only covered in cement paste, the hydration reaction that time made no difference to the strength of rubber concrete. And when the structure being broken, the broken part was still the interfacial transition zone. So the hydration reaction of mineral was no meaning. However, if we using the mixing process of cement paste encapsulating aggregate method, limiting the spread of mineral salt in the zone, there is some improvement with the strength of rubber concrete. So the hydration reaction is meaningful. And organic salt cannot do good to the hydration reaction with cement, So the modification effect of organic salt is weak than mineral salt.

\section{The Mixing Process of Rubber Powder[4]}

The traditional handicraft of rubber concrete usually mixed the concrete, sand, stone, rubber particle and water at one time. The way caused that concrete component and rubber particle lack of dispersion. And the interfacial transition zone has obvious problem in graded distribution so that reducing the strength of concrete. If used the traditional handicraft, it cannot reach the goal of modification. The reason why is that mineral salt will quickly dissolve in cement paste but not interfacial transition zone.

In order to prove the rationality of the encapsulating aggregate method, the paper made the rationality experiment. According to the $5 \%$ weight of rubber powder got the $\mathrm{Cacl}_{2}$, then confected them into solution of mixture concentration was $10 \%$.Soaked the rubber powder for $24 \mathrm{~h}$.And according to different handicraft to take care for rubber concrete specimens. Got the result of $28 \mathrm{~d}$ compressive strength of concrete, which is as chart 5: 
Tab.5 The 28d compressive strength of rubber concrete under different handicraft(MPa)

\begin{tabular}{l|c}
\hline encapsulating aggregate method & 41.1 \\
\hline traditional handicraft & 34.7 \\
\hline
\end{tabular}

\section{The Harmful Part of Mineral Salt to Concrete}

Although mineral salt is suitable for the modifier of rubber concrete, there are still do harm to concrete. The harmful part is that it can corrodes rebar.Causing volume expansion and so on. Those shortcoming limited mineral salt apply in rubber concrete. On the other hand, the experiment indicated that the suitable amount of admixture about mineral salt was low, which obeys the standard. In order to prevent the crrossion of rebar, we can used mineral salt with corrosion inhibitor, which making sure the benefit of mineral salt could totally show up. The most popular corrosion inhibition is thiethanolamine and the suitable amount of admixture is between $0.03 \%$ and $0.05 \%$

\section{Results}

The paper combines experiment with theretical analysis including the results were as follow:

(1)The influence of mineral salt to the compressive strength about pavement rubber concrete is obvious while it's nothing to splitting strength.

(2)The longer time of rubber concrete is soaked by mineral salt solution, the more apparent of modification effect.

(3)As modifier, the optimal usage of $\mathrm{Cacl}_{2}$ is $1 \%$ of rubber powder's weight. If it takes too much, the modification effect will getting poor.

(4)Rubber powder after treatment fits the mixing process of cement paste encapsulating aggregate method. This method has some effect on the hardness of interfacial transition zone.

(5)Organic salt isn't suitable for being modifier.

The paper remains some problem to save. Such as the sacking technology, the suitable length of drying time, the suitable drying temperature and how to recycle the residual salt. Those problems are going to get answer by other experiment analysis.

\section{Reference}

[1]shuai tian, ye li, weifeng li, ect. The research status and prospect about the pavement rubber concrete[J]concrete, 2011(7): 87-90.

[2]shuai tian, daning li, ninghe ding, The research of the optimal modifier about pavement rubber concrete powder[J]concrete, 2011(10): 72-74.

[3] haibo zhang, xuemao guan, xiao xing liu, ect. The influence of waste rubber concrete powder and the interface analysis[J]Material Review.2009(23), 65-67.

[4]haidong wang, zhixing zeng. The measure about how to increase the interface bond of rubber concrete[J]Journal of North China Institute of Water Conservancy and Hydroelectric Power, 2010(6), 57-60. 